\title{
APLASTIC ANEMIA
}

\author{
Neal S. Young, M.D. \\ Hematology Branch, National Heart, Lung and Blood Institute
}

Aplastic anemia is an historic disease. The first patient was described by the young Paul Ehrlich in 1885, "anemia aplastique" originated with Vaquez in 1904, and its clinical features were described by Cabot and other pathologists in the early $20^{\text {th }}$ century. In the modern era, an almost uniformly fatal prognosis, mainly for young persons with sudden severe pancytopenia, has been reversed, with development of effective therapies for almost all patients. In the research laboratory understanding of pathophysiology has guided development of therapies. Marrow failure syndromes have been linked viral infection and environmental toxins, inherited and acquired genetic mutations, to the early events in leukemogenesis, and to the hematopoiesis of normal aging.

\section{Definitions}

Aplastic anemia's long history has produced confusing terminology. "Anemia" derives from early ability to measure red blood cells in a hematocrit. Most patients have pancytopenia, with decreased platelets and white blood cells. "Aplastic" refers to the inability marrow to form blood, the end organ effect of diverse pathophysiologic mechanisms. Historically, identification of aplastic anemia was post-mortem, and the biopsy remains fundamental to diagnosis. Yet a seemingly empty bone marrow may be entirely capable of supporting normal hematopoiesis. Conversely, bone marrow failure can occur with normally cellular marrow, as in the myelodysplastic syndromes (MDS) and paroxysmal nocturnal hemoglobinuria (PNH).

\section{Pathophysiologies}

Three main pathophysiologies produce the pathology of an "empty" marrow (Figure 1).

\section{Direct Marrow Damage.}

Damage occurs most often iatrogenically, from chemotherapy and radiation. Marrow effects are dose-dependent and, at conventional doses, transient; other organ systems are affected; and spontaneous recovery is expected. Benzene, an inexpensive solvent, also damages hematopoiesis, and industrially exposed workers figured prominent in the early literature of aplastic anemia. Benzene now is a negligible risk factor, accounting for only a small etiologic fraction in most countries ${ }^{1,2}$. In China, rapidly industrialized and less regulated, benzene remains a workplace toxin ${ }^{3,4}$. Dosage is critical; workers with less intense and/or prolonged benzene exposure appear to suffer milder cytopenias, and they recover after 
terminating exposure. Marrow failure is a proximate effect, not a late consequence, of benzene exposure.

\section{Constitutional Syndromes.}

Marrow failure results from loss-of-function germline mutations, usually inherited (Table 1). A spectrum of genetic lesions diminish the hematopoietic stem's ability to repair DNA, as in Fanconi anemia (replication-dependent removal of inter-strand DNA cross-links) ${ }^{5}$ and dyskeratosis congenita (telomere maintenance and repair) ${ }^{6}$ or the stem and progenitor cells' differentiation and self-renewal pathways, as in $G A T A 2^{7}$. Marrow failure has been appreciated in syndromes affecting immune regulation, as in $C T L A 4^{8}$ and $D A D A 2 .{ }^{9}$ Constitutional syndromes classically appear in childhood, often with characteristic physical anomalies; typically organs other than marrow are involved; and family history often discloses affected relatives. Fatal graft rejection has followed inadvertent use of an affected sibling ${ }^{10}$ and persistent marrow failure after transplant in patients with mutations in the gene encoding the growth factor thrombopoietin. ${ }^{11}$ Results of published surveys from specialty clinics are dependent on referral patterns and case definitions. Among about 100 children and adults with aplastic anemia, $5 \%$ had genetic mutations on screening ${ }^{12}$. Of 173 patients, mostly under age 18 years, referred for diagnosis of constitutional marrow failure, about $50 \%$ showed mutations on genomic screening. ${ }^{13}$ At NIH, among children and adults referred for protocol treatments, only one of 74 patients with severe aplastic anemia had an unexpected pathogenic mutation; mutations were more prevalent in moderate aplastic anemia patients.

\section{Immune aplastic anemia.}

Almost all sporadic aplastic anemia, especially when severe and acute, appears to be immune-mediated. The strongest, most relevant evidence for an immune mechanism is the response of blood counts to a variety of immunosuppressive therapies and dependence of counts after recovery on maintenance calcineurin inhibitors ${ }^{14,15}$. Immune aplastic anemia lies in a spectrum of bone marrow and blood cell diseases (Figure 2A).

Cytotoxic $\mathrm{T}$ cells have been the focus in studies of patient samples and in vitro. These cells appear functionally and phenotypically activated ${ }^{16,17}$, skewed to produce type 1 cytokines ${ }^{18,19}$, induce apoptosis via Fas/FasL ${ }^{20}$, and circulate as oligoclones. ${ }^{21}$ Acquired, somatic mutations in the STAT3 signaling pathway may be pathogenic in some aplastic anemia, as they are in large granular lymphocytosis, producing constitutively activated $\mathrm{T}$ cells ${ }^{22}$. Treg cells are decreased in patients with aplastic anemia and increase with hematologic response. ${ }^{2324,25}$

Aplastic anemia is associated with specific histocompatibility antigens ${ }^{2627}$. More striking is the presence of "escape clones", granulocytes with loss of the region of chromosome 6 that encompasses HLA alleles, in 10-15\% of patients ${ }^{2829,30}$; cells selected by absence of HLA, acquired by $6 \mathrm{pLOH}$ or somatic mutations, sustain hematopoiesis by clonal expansion ${ }^{31}$ Immune escape has been hypothesized to explain clonal expansion of cells globally deficient in glycosylphosphoinositiol (GPI)-anchored proteins ${ }^{32}$ in PNH, due to an acquired mutation in $P I G-A$ in a stem cell. The GPI anchor itself has been suggested to be a target of the 
immune response. ${ }^{33}$ Autoantibodies, of uncertain significance, have been identified by high throughput screening of sera ${ }^{3435}$ but the inciting antigen(s) for the dominant $\mathrm{T}$ cell response remain unknown.

Immune aplastic anemia can be modeled in mice: infusion of mis-matched donor lymphocytes leads to rapid hematopoietic failure and death. ${ }^{3637}$ Limited numbers of T cells specifically attack marrow cells, produce apoptosis through Fas/FasL engagement; type 1 cytokines have an active role in target cell death, directly for IFN- $\gamma$, indirectly for TNF- $a$; and Tregs are modulatory.

\section{Hematopoiesis}

\section{Stem Cell Number.}

Aplastic anemia long has been regarded as the result of a profound deficit in hematopoietic stem and progenitor cells. The marrow is devoid of morphologic precursors to erythrocytes, granulocytes, and platelets. CD34 cells are almost completely absent in fixed biopsies or by flow cytometry. Colony forming cells for differentiated lineages and more immature multipotent cells are also extremely low in number.

None of the available measurements of hematopoiesis correlates closely with blood counts. More important, recovery of blood counts and of bone marrow function after immunosuppression and even more dramatically with growth factor stimulation indicates that stem cells are present even in the most deficient marrow. Assays to measure functional stem cells in humans are not quantitative, the contributions of true stem cells and more mature but still primitive multipotent progenitors to maintenance of hematopoiesis are controversial, and even changes with aging within the stem cell compartment have only been broadly defined.

\section{Stem Cell Clonality.}

Hematopoiesis in aplastic anemia is "clonal", but this is not a well-defined term ${ }^{38}$. Cancer is clonal: a tumor is derived from a single malignant cell. Clonality in marrow failure refers to the presence of populations originating from a single stem cell, which are easier to detect in circumstances of a failed bone marrow than in healthy individuals with hundreds of active stem cells. In aplastic anemia, benign clonal populations of granulocytes deficient in GPIanchored proteins or lacking HLA expression are frequent, presumably selected by survival under immune attack. Indeed, normal individuals have tiny numbers of leukocytes mutated in PIGA, and chromosomal clonal mosaicism is present in many normal tissues. "Clonal evolution" in aplastic anemia is development of MDS or acute myeloid leukemia (AML), characterized by aneuploidy, usually loss of all or a portion of chromosome 7. That similar chromosome abnormalities feature in both acquired ${ }^{39}$ and constitutional ${ }^{40}$ aplastic anemia suggests that the marrow failure environment itself predisposes to their selection.

With next generation sequencing, clonality is apparent in leukocytes mutated in a specific gene, in most studies a "candidate" gene known to be recurrently mutated in MDS and AML. ${ }^{41}$ In aplastic anemia, such clonal populations are present in about $1 / 3$ of patients, but in contrast to MDS and AML, a very limited set of genes (DNMT3A, ASXL1, and BCOR) 
is involved and the clone size (variant allele fraction) is small. ${ }^{42,43}$ The presence of a mutated clone in a patient associated with outcomes (BCOR and PIGA a favorable prognosis; mutations including $D N M T 3 A$ and $A S X L 1$, a worse prognosis). ${ }^{42}$ Paradoxically, mutated clones rarely appeared to drive evolution to a myeloid malignancy.

\section{Telomeres.}

Extremely short telomeres are typical of the patient with a genetic telomere disease. In immune aplastic anemia, telomere length may be decreased due to increased mitotic demand on a limited pool of stem cells. ${ }^{44}$ Telomere length at diagnosis has correlated with outcomes ${ }^{45,46}$, response to immunosuppression, ${ }^{47}$ and evolution to MDS and AML. ${ }^{45}$ Accelerated telomere attrition precedes progression to monosomy $7 .^{48}$

\section{Diagnosis}

A fatty bone marrow remains basic to diagnosis, but sophisticated testing now can be directed at distinguishing among diverse pathophysiologies and discriminating among similar, sometimes overlapping diseases whi in the differential diagnosis (Fig. 2B). Accurate diagnosis is required for appropriate therapy and effective management.

\section{Constitutional versus acquired bone marrow failure.}

Genomic screening complements functional testing for Fanconi anemia (chromosomes after clastogenic stress) and telomeropathies (telomere length). However, comprehensive germline screening adds to the cost of the evaluation, results may not return to the clinician for several weeks, and a report can be difficult to interpret. Screening for the approximately 50 genes that cause constitutional marrow failure is particularly valuable in moderate and chronic pancytopenia, thrombocytopenia, and macrocytic anemia; absent a family history, physical stigmata, or evidence of organ involvement beyond the marrow, it is not likely to be positive in severe pancytopenia. Commercial testing reports "pathogenic" mutations, a determination that relies on continual reannotation of the literature and judgements based on amino acid changes and their location in conserved or functionally critical regions of a gene. Some base substitutions are infrequent polymorphisms in certain ethnic populations, and their significance is uncertain. Conversely, exome sequencing of candidate genes may not detect critical mutations in regulatory regions. ${ }^{49,50}$ Correlation of genomics with functional testing is desirable, but some telomeropathy patients have normal telomere length, short telomeres not below the first percentile can be difficult to interpret, and mosaicism due to reversion of a Fanconi anemia gene can lead to a normal chromosome study in peripheral blood.

\section{Hypoplastic MDS versus aplastic anemia.}

Acquired mutations are detected on genomic screens of recurrently mutated genes in MDS and AML. Such testing is valuable when MDS is suspected. Hypocellular MDS may be suggested from the bone marrow appearance, especially dyspoietic megakaryocytes, ${ }^{51}$ and a normal or increased number of CD34 cells is not consistent with aplastic anemia. Flow cytometry enumerates CD34 cells and may show anomalous phenotypes indicating aberrant differentiation ${ }^{52}$. Genomics may be useful, as spliceosome gene mutations are prevalent in MDS but unusual in aplastic anemia, as is more than a single mutated gene. ${ }^{53}$ However, the 
genomic pattern of hypoplastic MDS, although distinct from normal or hypercellular MDS, is similar to the pattern in aplastic anemia, in the specific genes involved, the likelihood of only a single gene mutation, and smaller clone size. ${ }^{54}$ The finding of a DNMT3A- or ASXL1-mutated clone does not alter the diagnosis of aplastic anemia or likelihood of response to therapy.

\section{$\mathrm{PNH} /$ aplastic anemia syndrome.}

Screening for PNH is performed by flow cytometry, which precisely measures clone size as a proportion of GPI-anchored protein deficient cells by absence of specific antibody binding on erythrocytes and leukocytes. In hemolytic PNH, the clone is large, above 50\% and sometimes approaching representation of all circulating cells from the mutated clone. A large clone also correlates with the risk of catastrophic clots and is an indication for anticomplement therapy with eculizumab; eculizumab resolves intravascular hemolysis and is effective as thrombosis prophylaxis. Clones are much smaller in aplastic anemia, requiring monitoring but not treatment; clinical PNH is unlikely to develop from tiny clones or without a clone at diagnosis 55

\section{Treaments}

\section{Bone marrow transplantation (BMT).}

Replacement of a failed bone marrow is curative of the underlying disease. Transplant has been limited by its complications, graft rejection and graft-versus-host disease (GVHD), and the availability of suitable donors.

For immune aplastic anemia, transplant is always preferred in the young patient, and when undertaken expeditiously after diagnosis using a histocompatible sibling donor, results are excellent, with more than $90 \%$ long term survival in young children, ${ }^{56,57}$ more than $80 \%$ in adolescents $^{58}$, and a low rate of complications short- and long-term. While sibling donor transplant now is more frequent in older adults, results have not improved over several decades, remaining about $50 \%$ for recipients over 40 years of age ${ }^{59}$, almost 3 -fold higher than in children. ${ }^{60}$ African-Americans also have poorer outcomes compared to Caucasians. ${ }^{61}$ Marrow is the preferred source due to more GVHD using peripheral blood. ${ }^{62,63}$ Rabbit ATG is often added to the conditioning regimen ${ }^{64,65}$, and radiation, especially in children, avoided.

Histocompatible sibling donors are unavailable for most patients, but large donor registries provide the option of unrelated source HLA-matched at molecular resolution for most Caucasian patients. ${ }^{66-69}$ In a comprehensive report of over 500 transplants, outcome measured as survival was not statistically inferior to conventional matched sibling transplants, but the frequency of serious GVHD was two-fold higher ${ }^{67,68}$ Young age is a favorable factor for unrelated transplant as for sibling donor transplant. Children who have failed other therapies can receive unrelated grafts and have excellent survival, 95\% in a multicenter British study. ${ }^{70}$ Outcomes are better with use of marrow rather than blood donor cells, ATG in the conditioning, younger donors, and a shorter interval from diagnosis. ${ }^{67,68,71}$ Outcomes have been so good that some experts have advocated for first-line use of unrelated 
donors, ${ }^{72,73}$ despite sometimes protracted delays in identifying and collecting donor cells. Late effects are more frequent in recipients after unrelated compared to sibling donor transplants. ${ }^{74}$

Umbilical cord transplantation also has been successful in aplastic anemia, mainly in children due to the relationship between donor inoculum cell numbers and recipient weight, with survival approximating $90 \% .^{75,76}$ Rates of GVHD are low; the major disadvantage of cord blood is delayed engraftment and prolonged neutropenia. Some protocols combine cord and mismatched bone marrow ${ }^{77}$

A potential donor half matched to the patient should be present in virtually every family. As even single antigen disparities markedly affect outcomes of transplants, overcoming major histocompatibility differences had seemed an insuperable barrier. T cell depleting strategies, pre-transplant by cytotoxic drugs and biologics, and post-transplant with cyclophospamide ${ }^{78}$ have been utilized to prevent GVHD. Extensive experience in Chinese centers and smaller series of patients transplanted in the United States and Europe shows excellent results (Table 2). Haploidentical transplant has been advocated in China as first treatment for children. ${ }^{79}$; in Europe, with 1 year survival of about $77 \%$, haploidentical transplant is recommended as second-line therapy. ${ }^{80}$ Long-term effects of the complicated regimens and mismatched immune system are unknown but possibly they will be ameliorated by the low prevalence and severity of graft-versus-host disease.

For the constitutional marrow failure syndromes, specific considerations relate to the underlying biology, in Fanconi anemia the sensitivity of cells in many organs to alkylating agents in conditioning regimens, and the natural history of these diseases, resulting in late cancers in Fanconi anemia and organ failure in telomere disease. Both the decision to transplant and timing of transplant can be difficult, due to slow progression of moderate hematopoietic failure and the uncertainty of highly variable disease outcomes without intervention. Results generally have been less than optimal. ${ }^{8182,83}$ Worsening blood counts or evidence of progression to malignancy are obvious indications for transplant, and in some syndromes transplant has been remarkably effective. ${ }^{84}$

\section{Immunosuppression.}

In the early years of transplant, occasional autologous recovery of patient marrow suggested that the antilymphocyte globulin employed in conditioning might have had a salutary effect. Combined with cyclosporine, anti-thymocyte globulin (ATG) leads to hematologic responses in about $2 / 3$ of patients. ${ }^{1480}$ ATGs are complex, not fully defined mixtures of antibodies to human proteins. ATGs are relatively mildly lymphocyte depleting but subtle differences in mechanism of action appear important for efficacy. For example, rabbit ATG was much less efficacious than was horse ATG in a randomized controlled trial, in which a major difference in biologic effect was more severe depletion of $\mathrm{CD} 4$ cells and T regulatory cells following rabbit ATG. ${ }^{25}$ Even with response, most patients do not recover normal blood counts. About $1 / 3$ patients relapse or require cyclosporine long-term to maintain their response. ${ }^{85}$; relapse usually responds to further immunosuppression. ${ }^{86}$ Responses and outcomes are better in children than in older adults. ${ }^{87,8889}$ Patients who do not respond to horse ATG may improve with second line rabbit ATG or alemtuzumab, a pan-T cell monoclonal antibody. ${ }^{86}$ 
Immunosuppressive therapy is less arduous than transplant and is available to all patients, but, in not replacing the affected marrow or immune system, late consequences of the disease can occur. Not infrequent relapse can be ameliorated but obligates the patient to long term cyclosporine. More serious is "clonal evolution", the later development of MDS or AML, even after stable blood count recovery. Clonal evolution most often manifests as a cytogenetic abnormality, usually loss of all or part of chromosome $7^{39}$ and occurs in about $15 \%$ of aplastic anemia patients over the decade following initial immunosuppression. ${ }^{14}$ Chromosome 7 aneuploidy has a poor prognosis and triggers efforts to transplant.

\section{Stem Cell Stimulation.}

Attempts to improve on ATG by addition of androgens, granulocyte colony stimulating factor, mycophenolate, or rapamycin have not altered response rates or long-term outcomes. Hematopoietic growth factors are ineffective in aplastic anemia. It was therefore unexpected when eltrombopag, a synthetic mimetic of thrombopoietin, showed activity in patients with refractory aplastic anemia, about half of whom responded with robust trilineage improvements in blood counts, most durable after discontinuation of drug. ${ }^{9091}$ Eltrombopag has been relabeled for this indication. When eltrombopag was added to initial standard immunosuppression, it markedly increased the overall response rate to about $80 \%$ and the complete response rate to about $50 \%$, with patients often showing more rapid than expected hematologic recovery. ${ }^{46}$ To date, the rates of relapse and evolution to myeloid malignancies appear similar or lower than in historical controls treated with immunosuppression alone.

Increased bone marrow cellularity, CD34 cell and progenitor numbers suggest a direct effect of eltrombopag on marrow stem cells. ${ }^{46}$ Thrombopoietin concentrations in the blood of aplastic anemia patients are very high ${ }^{92,93}$, but eltrombopag may evade a block to receptor engagement in the presence of interferon- $\gamma$ (Alvarado and Larochelle, personal communication).

\section{Androgens.}

Androgens are historic therapy for marrow failure syndromes. While generally regarded as much less efficacious in severe aplastic anemia than are immunosuppressive strategies, androgens are standard care for many constitutional syndromes. Sex hormones increase expression of the gene for telomerase in cell culture ${ }^{94}$ and in mice..$^{95} \mathrm{In}$ a recent prospective trial, high doses of danazol, a synthetic androgen, improved blood counts in patients with telomere disease and also appeared to reverse accelerated telomere attrition. ${ }^{96}$

Provisional treatment algorithms are provided in Figure 3.

\section{Conclusion}

Aplastic anemia is a remarkable story of success in the clinic and the laboratory, with implications beyond bone marrow failure. Its etiologies relate to common environmental toxins, to specific viral infections, and to genes affecting basic cellular mechanisms; the role of the immune system has been appreciated as both potent and subtle. Most gratifying, treatments for the patient with immune aplastic anemia have improved remarkably over the last several decades, due to the development of better transplant and immunosuppression 
regimens. Transplant can be beneficial in all types of marrow failure, but in the future gene editing and modulation offer hope for constitutional diseases.

\section{Acknowledgements}

The author appreciates careful reading of the manuscript by colleagues James Cooper, Valentine Giudice, Clare Sun, Philip Scheinberg, and Danielle Townsley.

Supported by NHLBI Intramural Research Program.

\section{References}

1. Kaufman DW, Kelly JP, Levy M, Shapiro S. The Drug Etiology of Agranulocytosis and Aplastic Anemia. New York: Oxford; 1991.

2. Issaragrisil S, Kaufman D, Anderson T, et al. The epidemiology of aplastic anemia in Thailand. Blood 2006;107:1299-307. [PubMed: 16254144]

3. Yang C, Zhang X. Incidence survey of leukemia in China. Chinese Medical Sciences Journal 1991;6:65-70. [PubMed: 1804379]

4. Gross SA, Irons RD, Schnatter AR, et al. A hospital-based case control study of aplastic anemia in Shanghai, China. Chem Biol Interact 2010;184:165-73. [PubMed: 20026322]

5. Garaycoechea JI, Patel KJ. Why does the bone marrow fail in Fanconi anemia? Blood 2014;123:2634. [PubMed: 24200684]

6. Savage SA, Dufour C. Classical inherited bone marrow failure syndromes with high risk for myelodysplastic syndrome and acute myelogenous leukemia. Semin Hematol 2017;54:105-14. [PubMed: 28637614]

7. Wlodarski MW, Niemeyer CM, Brown AL, et al. Genetic Syndromes Predisposing to Myeloid Neoplasia: Elsevier Incorporated; 2017.

8. Kuehn HS, Ouyang W, Lo B, et al. Immune dysregulation in human subjects with heterozygous germline mutations in CTLA4. Science 2014;345:1623-7. [PubMed: 25213377]

9. Michniacki TF, Hannibal M, Ross CW, et al. Hematologic manifestations of deficiency of adenosine deaminase 2 (DADA2) and response to tumor necrosis factor inhibition in DADA2-associated bone marrow failure. J Clin Immunol 2018;38:166-73. [PubMed: 29411230]

10. Fogarty P, Yamaguchi H, Wiestner A, et al. Late presentation of dyskeratosis congenita as apparently acquired aplastic anaemia due to mutations in telomerase RNA. Ann Int Med 2003;362:1628-30.

11. Seo A, Ben-Harosh M, Sirin M, et al. Bone marrow failure unresponsive to bone marrow transplant is caused by mutations in thrombopoietin. Blood 2017;130:875-80. [PubMed: 28559357]

12. Keel SB, Scott A, Sanchez-Bonilla M, et al. Genetic features of myelodysplastic syndrome and aplastic anemia in pediatric and young adult patients 1. Haematologica 2016.

13. Bluteau O, Sebert M, Leblanc T, et al. A landscape of germline mutations in a cohort of inherited bone marrow failure patients. Blood 2017:blood-2017-09-806489.

14. Scheinberg P, Young NS. How I treat aplastic anemia. Blood 2012;120:1185-96. [PubMed: 22517900]

15. Thota S, Patel BJ, Sadaps M, et al. Therapeutic outcomes using subcutaneous low dose alemtuzumab for acquired bone marrow failure conditions. British Journal of Haematology 2017.

16. Zoumbos NC, Gascon P, Djeu JY, Trost SR, Young NS. Circulating activated suppressor T lymphocytes in aplastic anemia. N Engl J Med 1985;312:257-65. [PubMed: 2981406]

17. Hosokawa K, Muranski P, Feng X, et al. Memory stem T cells in autoimmune disease: high frequency of circulating CD8+ memory stem T cells in acquired aplastic anemia. J Immunol 2015; 196:1568-78.

18. Solomou EE, Keyvanfar K, Sloand EM, Weinstein B, Nunez O, Young NS. T-bet over-expression in T cells from patients with aplastic anemia. Blood 2005;106:245a-a. 
19. Smith JN, Kanwar VS, MacNamara KC. Hematopoietic stem cell Regulation by type I and II interferons in the pathogenesis of acquired aplastic anemia. Front Immunol 2016;7:330. [PubMed: 27621733]

20. Liu C, Fu R, Wang H, et al. Fas/FasL in the immune pathogenesis of severe aplastic anemia. Genet Mol Res 2014;13:4083-8. [PubMed: 24938700]

21. Giudice V, Feng X, Lin Z, et al. Deep sequencing and flow cytometric characterization of expanded effector memory CD8+CD57+ T cells frequently reveals T-cell receptor V $\beta$ oligoclonality and CDR3 homology in acquired aplastic anemia. Haematologica 2018:739-69.

22. Jerez A, Clemente MJ, Makishima H, et al. STAT3-Mutations indicate the presence of subclinical self-reactive cytotoxic T cell clones in aplastic anemia and myelodysplastic syndromes. Blood (ASH Annual Meeting 2012) 2012:646.

23. Solomou EE, Rezvani K, Mielke S, et al. Deficient CD4+ CD25+ FOXP3_ T regulatory cells in acquired aplastic anemia. Blood 2007;110:1603-11. [PubMed: 17463169]

24. Kordasti S, Costantini B, Seidl T, et al. Deep-phenotyping of Tregs identifies an immune signature for idiopathic aplastic anemia and predicts response to treatment. Blood 2016;128:1193-205. [PubMed: 27281795]

25. Scheinberg P, Nunez O, Weinstein B, Scheinberg P, Wu CO, Young NS. Horse versus rabbit antithymocyte globulin in acquired aplastic anemia. N Engl J Med 2011;365:430-8. [PubMed: 21812672]

26. Deng X-Z, Du M, Peng J, et al. Associations between the HLA-A/B/DRB1 polymorphisms and aplastic anemia: evidence from 17 case-control studies. Hematology 2017:1-9.

27. Liu S, Li Q, Zhang Y, et al. Association of human leukocyte antigen DRB1* 15 and DRB1* 15: 01 polymorphisms with response to immunosuppressive therapy in patients with aplastic anemia: a meta-analysis. PloS One 2016;11:e0162382. [PubMed: 27611583]

28. Katagiri T, Sato-Otsubo A, Kashiwase K, et al. Frequent loss of HLA alleles associated with copy number-neutral 6pLOH in acquired aplastic anemia. Blood 2011;118:6601-9. [PubMed: 21963603]

29. Babushok DV, Duke JL, Xie HM, et al. Somatic HLA mutations expose the role of class Imediated autoimmunity in aplastic anemia and its clonal complications. Blood Advances 2017;1:1900-10. [PubMed: 28971166]

30. Betensky M, Babushok D, Roth JJ, et al. Clonal evolution and clinical significance of copy number neutral loss of heterozygosity of chromosome arm $6 \mathrm{p}$ in acquired aplastic anemia. Cancer genetics 2016;209:1-10. [PubMed: 26702937]

31. Imi T, Katagiri T, Hosomichi K, et al. Sustained clonal hematopoiesis by HLA-lacking hematopoietic stem cells without driver mutations in aplastic anemia. Blood Adv 2018;2:1000-12. [PubMed: 29720492]

32. Luzzatto L, Notaro R. The "escape" model: a versatile mechanism for clonal expansion. Br J Haematol 2018.

33. Gargiulo L, Zaimoku Y, Scappini B, et al. Glycosylphosphatidylinositol-specific T cells, IFN- $\gamma$ producing T cells, and pathogenesis of idiopathic aplastic anemia. Blood 2017;129:388-92. [PubMed: 27903525]

34. Feng X, Chuhjo T, Sugimori C, et al. Diazepam-binding inhibitor-related protein 1: a candidate autoantigen in acquired aplastic anemia patients harboring a minor populatoin of paroxysmal nocturnal hemoglobinuria-type cells. Blood 2004;104:2425-31. [PubMed: 15217832]

35. Hirano N, Butler MO, von Bergwelt-Baildon MS, et al. Autoantibodies frequently detected in patients with aplastic anemia. Blood 2003;102:4567-75. [PubMed: 12947009]

36. Chen J Animal models for acquired bone marrow failure syndromes. Clin Med Res 2011;3:102-8.

37. Chen J, Feng X, Desierto MJ, Keyvanfar K, Young NS. IFN- $\gamma$-mediated hematopoietic cell destruction in murine models of immune-mediated bone marrow failure. Blood 2015;126:262131. [PubMed: 26491068]

38. Cooper JN, Young NS. Clonality in context: hematopoietic clones in their marrow environment. Blood 2017;130:2363-72. [PubMed: 29046282]

39. Maciejewski JP, Selleri C. Evolution of clonal cytogenetic abnormalities in aplastic anemia. Leukemia and Lymphoma 2004;45:433-40. [PubMed: 15160903] 
40. Pezeshki A, Podder S, Kamel R, Corey SJ. Monosomy 7/del (7q) in inherited bone marrow failure syndromes: A systematic review. Pediatr Blood Cancer 2017;64.

41. Ogawa S Clonal hematopoiesis in acquired aplastic anemia. Blood 2016;128:337-47. [PubMed: 27121470]

42. Yoshizato T, Dumitriu B, Hosokawa K, et al. Somatic mutations and clonal hematopoiesis in aplastic anemia. N Engl J Med 2014;373:35-47.

43. Kulasekararaj AG, Jiang J, Smith AE, et al. Somatic mutations identify a subgroup of aplastic anemia patients who progress to myelodysplastic syndrome. Blood 2014;124:2698-704. [PubMed: 25139356]

44. Townsley DM, Dumitriu B, Young NS. Bone marrow failure and the telomeropathies. Blood 2014;124:2775-83. [PubMed: 25237198]

45. Scheinberg P, Cooper JN, Sloand EM, Wu CO, Calado RT, Young NS. Association of telomere length of peripheral blood leukocytes predicts hematopoietic relapse, malignant transformation, and survival in severe aplastic anemia. JAMA 2010;304:1358-64. [PubMed: 20858879]

46. Townsley DM, Scheinberg P, Winkler T, et al. Eltrombopag added to standard immunosuppression for aplastic anemia. N Engl J Med 2017;376:1540-50. [PubMed: 28423296]

47. Narita A, Muramatsu H, Sekiya Y, et al. Paroxysmal nocturnal hemoglobinuria and telomere length predicts response to immunosuppressive therapy in pediatric aplastic anemia. Haematologica 2015;100:1546-52. [PubMed: 26315930]

48. Dumitriu B, Feng X, Townsley DM, et al. Telomere attrition and candidate gene mutations preceding monosomy 7 in aplastic anemia. Blood 2014;125:706-9. [PubMed: 25406353]

49. Aalbers AM, Kajigaya S, van den Heuvel-Eibrink MM, van der Velden VHJ, Calaco RT, Young NS. Human telomere disease due to disruption of the CCAAT box of the TERC promoter. Blood 2011;119:3060-3.

50. Hsu AP, Johnson KD, Falcone EL, et al. GATA2 haploinsufficiency caused by mutations in a conserved intronic element leads to MonoMAC syndrome. Blood 2013;121:3830-7, S1-7.

51. Bennett JM, Orazi A. Diagnostic criteria to distinguish hypocillular acute myeloid leukemia from hypocellular myelodysplastic syndromes and aplastic anemia: recommendations for a standardized approach. Haematologica 2009;94:264-8. [PubMed: 19144661]

52. Cremers EMP, Westers TM, Alhan C, et al. Multiparameter flow cytometry is instrumental to distinguish myelodysplastic syndromes from non-neoplastic cytopenias. Eur J Cancer 2016;54:4956. [PubMed: 26720403]

53. Malcovati L, Gallì A, Travaglino E, et al. Clinical significance of somatic mutation in unexplained blood cytopenia. Blood 2017:blood-2017-01-763425.

54. Nazha A, Seastone D, Radivoyevitch T, et al. Genomic patterns associated with hypoplastic compared to hyperplastic myelodysplastic syndromes. Haematologica 2015;100:e434-7. [PubMed: 26273060]

55. Bat T, Abdelhamid ON, Balasubramanian SK, et al. The evolution of paroxysmal nocturnal haemoglobinuria depends on intensity of immunosuppressive therapy. Br J Haematol 2017.

56. Dufour C, Pillon M, Socie G, et al. Outcome of aplastic anaemia in children. A study by the severe aplastic anaemia and paediatric disease working parties of the European group blood and bone marrow transplant. Br J Haematol 2015;169:565-73. [PubMed: 25683884]

57. Yoshida N, Kobayashi R, Yabe H, et al. First-line treatment for severe aplastic anemia in children: bone marrow transplantation from a matched family donor versus immunosuppressive therapy. Haematologica 2014;99:1784-91. [PubMed: 25193958]

58. Dufour C, Pillon M, Passweg J, et al. Outcome of aplastic anemia in adolescence: a survey of the Severe Aplastic Anemia Working Party of the European Group for Blood and Marrow Transplantation. Haematologica 2014;99:1574-81. [PubMed: 25085353]

59. Giammarco S, Peffault de Latour R, Sica S, et al. Transplant outcome for patients with acquired aplastic anemia over the age of 40: has the outcome improved? Blood 2018;131:1989-92. [PubMed: 29549172]

60. Gupta V, Eapen M, Brazauskas R, et al. Impact of age on outcomes after bone marrow transplantation for acquired aplastic anemia using HLA-matched sibling donors. Haematologica 2010;95:2119-25. [PubMed: 20851870] 
61. Eckrich MJ, Ahn KW, Champlin RE, et al. Effect of race on outcomes after allogeneic hematopoietic cell transplantation for severe aplastic anemia. Am J Hematol 2014;89:125-9. [PubMed: 24122901]

62. Schrezenmeier H, Passweg JR, Marsh JCW, et al. Worse outcome and more chronic GVHD with peripheral blood progenitor cells than bone marrow in HLA-matched sibling donor tranplants for young patients with severe aplastic anemia. Blood 2007;110:1397-400. [PubMed: 17475907]

63. Eapen M, Le RJ, Antin JH, et al. Effect of stem cell source on outcomes after unrelated donor transplantation in severe aplastic anemia. Blood 2011;118:2618-21. [PubMed: 21677312]

64. Champlin RE, Perez WS, Passweg JR, et al. BOne marrow transplantation for severe aplastic anemia: a radnomized controlled study of conditioning regimens. Blood 2007;109:4582-95. [PubMed: 17272503]

65. Kekre N, Zhang Y, Zhang M-J, et al. Effect of antithymocyte globulin source on outcomes of bone marrow transplantation for severe aplastic anemia. haematologica 2017;102:1291-8. [PubMed: 28341733]

66. Peinemann F, Grouven U, Kroger N, Pittler M, Zschorlich B, Lange S. Unrelated donor stem cell transplantation in acquired severe aplastic anemia: a systematic review. Haematologica 2009:1732-42. [PubMed: 19648165]

67. Kekre N, Antin JH. Hematopoietic stem cell transplantation donor sources in the 21st century: choosing the ideal donor when a perfect match does not exist. Blood 2014;124:334-43. [PubMed: 24914138]

68. Bacigalupo A, Sica S. Alternative donor transplants for severe aplastic anemia: current experience 1. Semin Hematol 2016;53:115-9. [PubMed: 27000736]

69. Eapen M, Horowitz MM. Alternative donor transplantation for aplastic anemia. Hematology Am Soc Hematol Educ Program 2010;2010:43-6. [PubMed: 21239769]

70. Samarasinghe S, Steward C, Hiwarkar P, et al. Excellent outcome of matched unrelated donor transplantation in paediatric aplastic anaemia following failure with immunosuppressive therapy: a United Kingdom multicentre retrospective experience. Br J Haematol 2012;157:339-46. [PubMed: 22372373]

71. Arai Y, Kondo T, Yamazaki H, et al. Allogeneic unrelated bone marrow transplantation from older donors results in worse prognosis in recipients with aplastic anemia. Haematologica 2016;101:644-52. [PubMed: 26858357]

72. Dufour C, Veys P, Carraro E, et al. Similar outcome of upfront-unrelated and matched sibling stem cell transplantation in idiopathic paediatric aplastic anaemia. A study on behalf of the UK Paediatric BMT Working Party, Paediatric Diseases Working Party and Severe Aplastic Anaemia Working Party of EBMT. Br J Haematol 2015;171:585-94. [PubMed: 26223288]

73. Mackarel J, Iatan M, Kumar L, Storey L, O’Marcaigh A, Smith O. In support of upfront stem cell transplantation as first-line therapy for paediatric patients with idiopathic severe aplastic anaemia who lack a sibling donor. Br J Haematol 2016.

74. Buchbinder D, Nugent DJ, Brazauskas R, et al. Late effects in hematopoietic cell transplant recipients with acquired severe aplastic anemia: a report from the late effects working committee of the center for international blood and marrow transplant research. Biol Blood Marrow Transplant 2012;18:1776-84. [PubMed: 22863842]

75. Pagliuca S, de Latour RP, Volt F, et al. Long Term Outcomes of Cord Blood Transplantation From an HLA-Identical Sibling for Patients with Bone Marrow Failure Disorders: a Report From Eurocord, Cord Blood Committee (CBC-CTIWP) and Severe Aplastic Anemia Working Party (SAAWP) of the European Society of Blood and Marrow Transplantation (EBMT). Biol Blood Marrow Transplant 2017.

76. Ades L, Mary JY, Robin M, et al. Long-term outcome after bone marrow transplantation for severe aplastic anemia. Blood 2004;103:2490-7. [PubMed: 14656884]

77. van Besien K, Childs R. Haploidentical cord transplantation-The best of both worlds. Semin Hematol 2016;53:257-66. [PubMed: 27788764]

78. Robinson TM, O’Donnell PV, Fuchs EJ, Luznik L. Haploidentical bone marrow and stem cell transplantation: experience with post-transplantation cyclophosphamide. Semin Hematol 2016;53:90-7. [PubMed: 27000732] 
79. Cheng Y, Xu Z, Zhang Y, et al. First-line choice for severe aplastic anemia in children: transplantation from a haploidentical donor vs immunosuppressive therapy. Clin Transplant $2018 ; 32$.

80. Bacigalupo A How I treat acquired aplastic anemia. Blood 2017;129:1428-36. [PubMed: 28096088]

81. Alter BP. Inherited bone marrow failure syndromes: considerations pre- and posttransplant. Blood 2017;130:2257-64. [PubMed: 29167174]

82. Alter BP. Inherited bone marrow failure syndromes: introduction In: Young NS, Alter BP, eds. Aplastic Anemia, Acquired and Inherited. Philadelphia: W.B. Saunders; 1994:271-4.

83. Elmahadi S, Muramatsu H, Kojima S. Allogeneic hematopoietic stem cell transplantation for dyskeratosis congenita. Curr Opin Hematol 2016;23:501-7. [PubMed: 27607446]

84. Parta M, Shah NN, Baird K, et al. Allogeneic Hematopoietic Stem Cell Transplantation for GATA2 Deficiency Using a Busulfan-Based Regimen. Biol Blood Marrow Transplant 2018.

85. Scheinberg P, Rios O, Scheinberg P, Weinstein B, Wu CO, Young NS. Prolonged cyclosporine administration after antithymocyte globulin delays but does not prevent relapse in severe aplastic anemia. Am J Hematol 2014;89:571-4. [PubMed: 24971433]

86. Scheinberg P, Nunez O, Weinstein B, Scheinberg P, Wu CO, Young NS. Activity of alemtuzumab monotherapy in treatment-naive, relapsed, and refractory severe acquired aplastic anemia. Blood 2012;119:345-54. [PubMed: 22067384]

87. Scheinberg P, Wu CO, Nunez O, Young NS. Long term outcome of pediatric patients treated with antithymocyte globulin and cyclosporin. J Pediatr 2008;153:814-9. [PubMed: 18672253]

88. Calado RT, Cooper JN, Padilla-Nash HM, et al. Short telomeres result in chromosomal instability in hematopoietic cells and precede malignant evolution in human aplastic anemia. Leukemia 2012;26:700-7. [PubMed: 22005790]

89. Tichelli A, Socié G, Henry-Amar M, et al. Effectiveness of immunosuppressive therapy in older patients with aplastic anemia. The European Group for Blood and Marrow Transplantation Several Aplastic Anaemia Working Party. Ann Intern Med 1999;130:193-201. [PubMed: 10049197]

90. Olnes MJ, Scheinberg P, Calvo KR, et al. Eltrombopag and improved hematopoiesis in refractory aplastic anemia. N Engl J Med 2012;367:11-9. [PubMed: 22762314]

91. Desmond R, Townsley DM, Dumitriu B, et al. Eltrombopag restores trilineage hematopoiesis in refractory severe aplastic anemia that can be sustained on discontinuation of drug. Blood 2014;123:1818-25. [PubMed: 24345753]

92. Schrezenmeier H, Griesshammer M, Hornkohl A, et al. Thrombopoietin serum levels in patients with aplastic anaemia: correlation with platelet count and persistent elevation in remission. $\mathrm{Br} \mathbf{J}$ Haematol 1998;100:571-6. [PubMed: 9504643]

93. Zhao X, Feng X, Wu Z, et al. Persistent elevation of plasma thrombopoietin levels after treatment in severe aplastic anemia. Exp Hematol 2018;58:39-43. [PubMed: 28941711]

94. Calado RT, Yewdell WT, Wilkerson KL, et al. Sex hormones, acting on the TERT gene, increase telomerase activity in human primary hematopoietic cells. Blood 2009;114:2236-43. [PubMed: 19561322]

95. Bar C, Huber N, Beier F, Blasco MA. Therapeutic effect of androgen therapy in a mouse model of aplastic anemia produced by short telomeres. Haematologica 2015;100:1267-74. [PubMed: 26206796]

96. Townsley DM, Dumitriu B, Liu D, et al. Danazol treatment for telomere diseases. N Engl J Med 2016;374:1922-31. [PubMed: 27192671]

97. Koh KN, Im HJ, Kim BE, et al. Haploidentical haematopoietic stem cell transplantation using CD3 or CD3/CD19 depletion and conditioning with fludarabine, cyclophosphamide and antithymocyte globulin for acquired severe aplastic anaemia. Br J Haematol 2011.

98. Clay J, Kulasekararaj AG, Potter V, et al. Nonmyeloablative peripheral blood haploidentical stem cell transplantation for refractory severe aplastic anemia. Biol Blood Marrow Transplant 2014;20:1711-6. [PubMed: 25016195]

99. Esteves I, Bonfim C, Pasquini R, et al. Haploidentical BMT and post-transplant Cy for severe aplastic anemia: a multicenter retrospective study. Bone Marrow Transplant 2015. 
100. Xu L-P, Wang S-Q, Wu D-P, et al. Haplo-identical transplantation for acquired severe aplastic anaemia in a multicentre prospective study. Brit J Haem 2016.

101. Xu L, Zhang X, Wang F, et al. Haploidentical transplantation for pediatric patients with acquired severe aplastic anemia. Bone marrow transplantation 2017;52:381-7. [PubMed: 27941773]

102. Xu L-P, Jin S, Wang S-Q, et al. Upfront haploidentical transplant for acquired severe aplastic anemia: registry-based comparison with matched related transplant. J Hematol Oncol 2017;10:25. [PubMed: 28107815]

103. DeZern AE, Zahurak M, Symons H, Cooke K, Jones RJ, Brodsky RA. Alternative donor transplantation with high-dose post-transplantation cyclophosphamide for refractory severe aplastic anemia. Biology of Blood and Marrow Transplantation 2017;23:498-504. [PubMed: 28013015]

104. Lu Y, Sun RJ, Zhao YL, et al. Unmanipulated haploidentical hematopoietic stem cell transplantation achieved outcomes comparable with matched unrelated donor transplantation in young acquired severe aplastic anemia. Biol Blood Marrow Transplant 2018.

105. Valdez JM, Scheinberg P, Nunez O, Wu C, Young NS, Walsh TJ. Decreased infection-related mortality and improved survival in severe aplastic anemia in the past two decades. Clinical Infectious Diseases 2011;52:726-35. [PubMed: 21367725]

106. Purev E, Tian X, Aue G, et al. Allogeneic transplantation using Cd34+ selected peripheral blood progenitor cells combined with non-mobilized donor T cells for refractory severe aplastic anaemia. Br J Haematol 2017;176:950-60. [PubMed: 28169418]

107. Kim SY, Le Rademacher J, Antin JH, et al. Myelodysplastic syndrome evolving from aplastic anemia treated with immunosuppressive therapy: efficacy of hematopoietic stem cell transplantation. Haematologica 2014;99:1868-75. [PubMed: 25107891] 


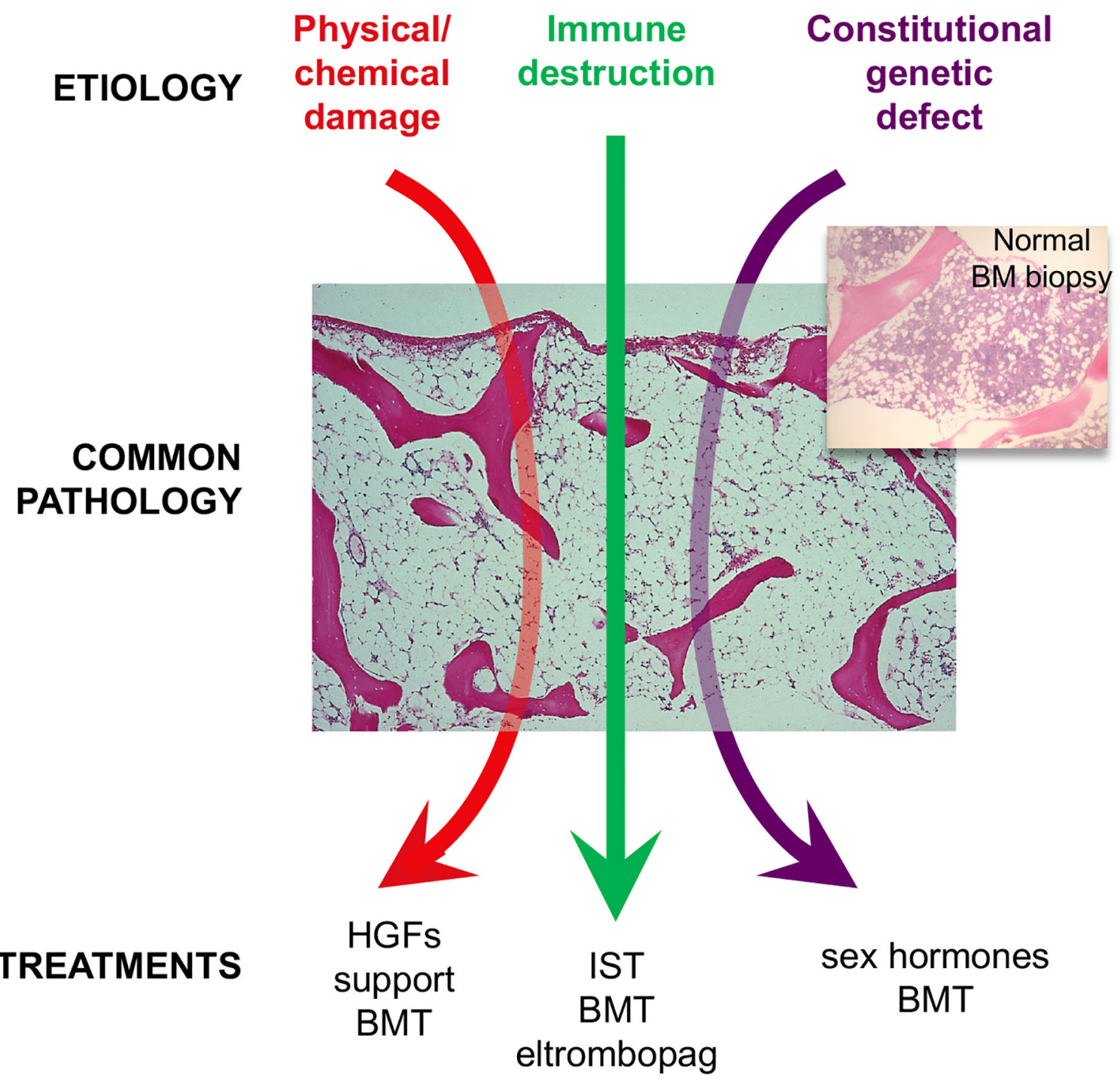

Figure 1.

Pathophysiologies of aplastic anemia. The common pathology of the bone marrow replaced by fat can result from chemical or physical damage (iatrogenic; benzene); immune destruction (mainly T cells); and as a constitutional defect in genes important in maintenance of cell integrity and immune regulation. $\mathrm{HGF}=$ hematopoietic growth factors; $\mathrm{BMT}=$ bone marrow transplantation; IST=immunosuppression. 

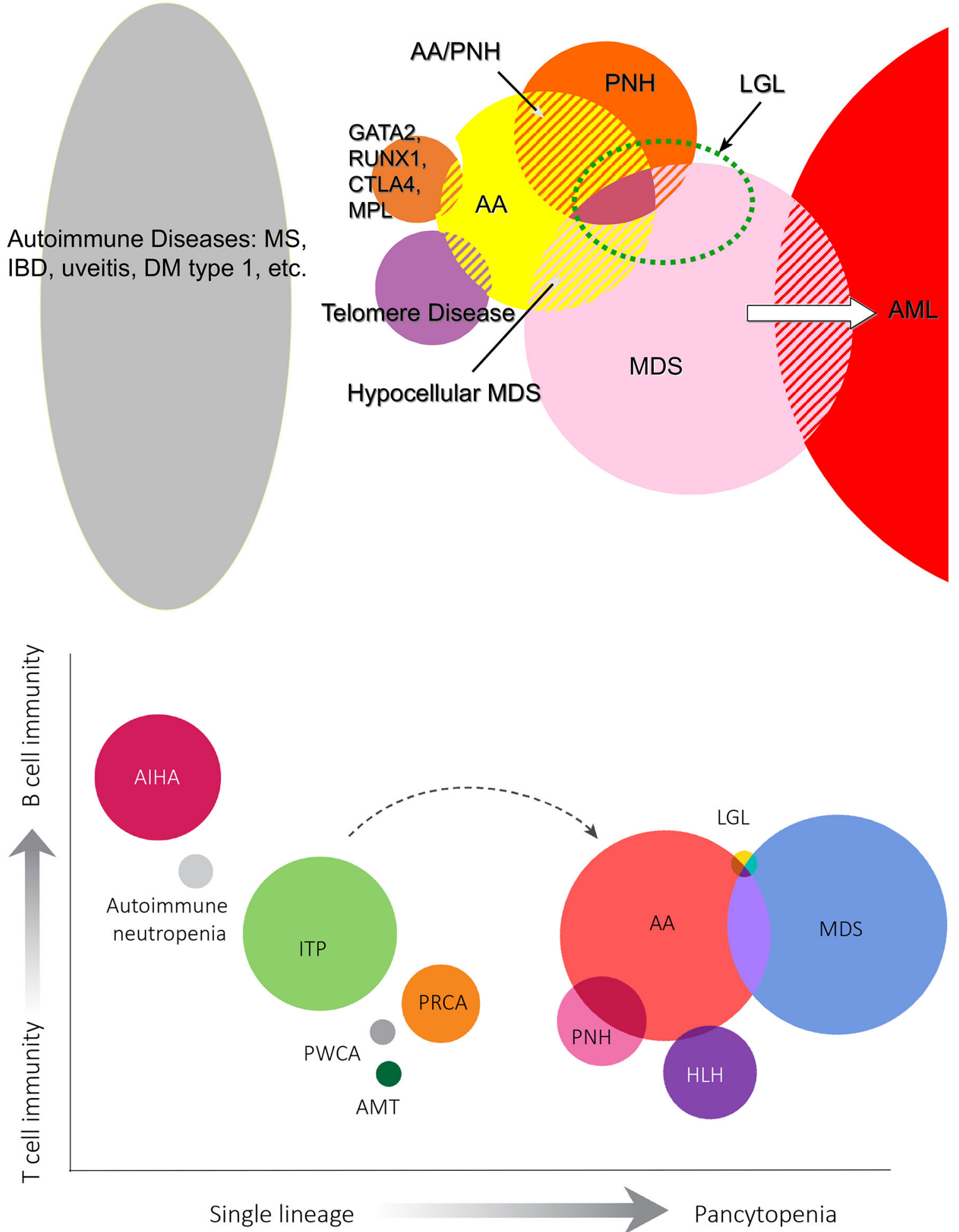

Figure 2.

Aplastic anemia in relationship to other diseases. A) Venn diagram emphasizing overlap of aplastic anemia, both diagnostic and pathophysiologic, with PNH, MDS, and constitutional marrow failure syndromes, as well as to other immune-mediated diseases in which a single 
organ is targeted. B) Spectrum of immune cytopenias. The consensus for dominant immune effectors is delineated on the y axis; for examples, autoimmune peripheral blood cell destruction is mainly antibody mediated, whereas $\mathrm{T}$ cells have been implicated in marrow destruction. However, the immune response is almost certainly complex in all these diseases. AA=aplastic anemia; $\mathrm{PNH}=$ paroxysmal nocturnal hemoglobinuria; $\mathrm{LGL}=$ large granular lymphocytosis; MDS=myelodysplastic syndromes; $\mathrm{AML}=$ acute myeloid leukemia; MS=multiple sclerosis; IBD=inflammatory bowel disease; $\mathrm{DM}=$ diabetes mellitus; ITP= immune thrombocytopenic purpura; AIHA=autoimmune hemolytic anemia; PRCA=pure red cell aplasia; PWCA=pure white cell aplasia; AMT=amegakaryocytic thrombocytopenia; HLH=hemophagocytic lymphohistiocytosis. (For schematic purposes the circles in the Venn diagram have been scaled to PubMed citations.) 

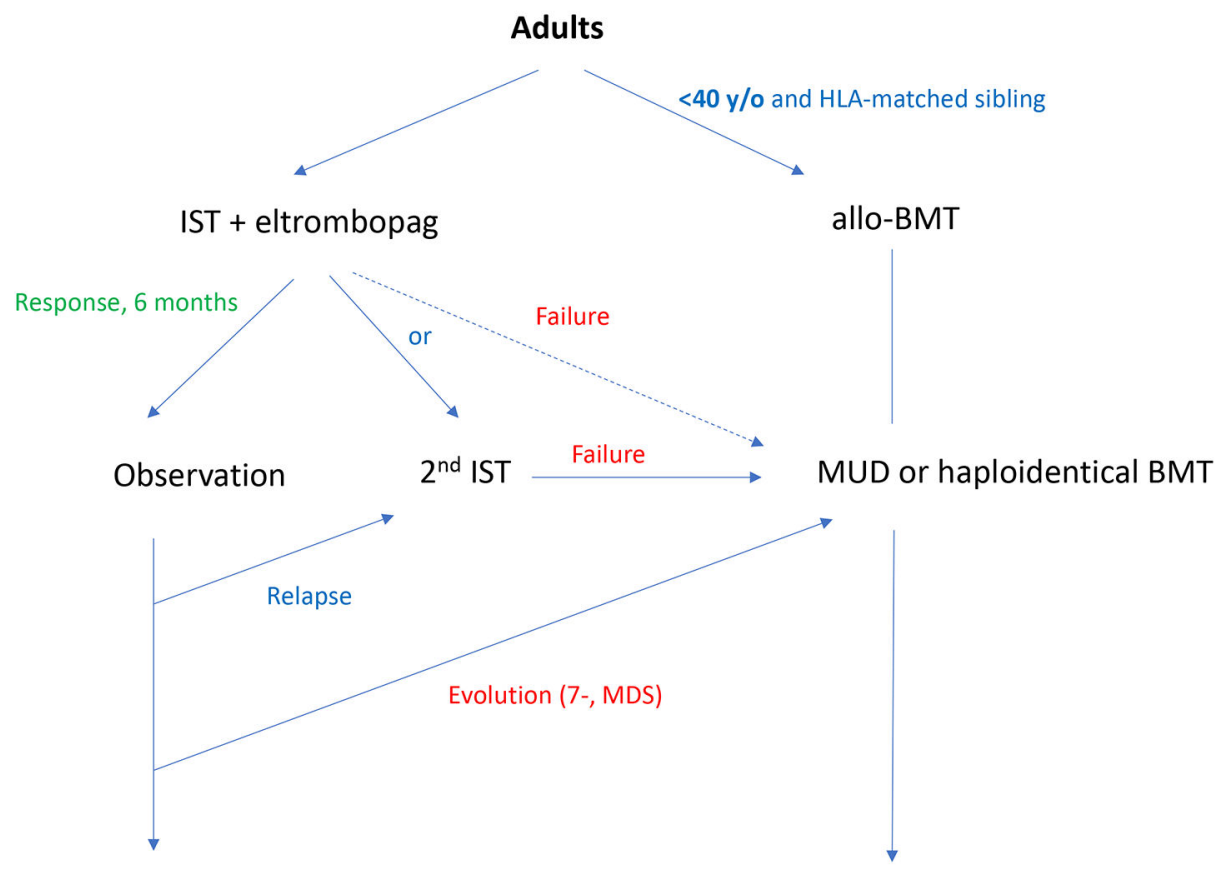


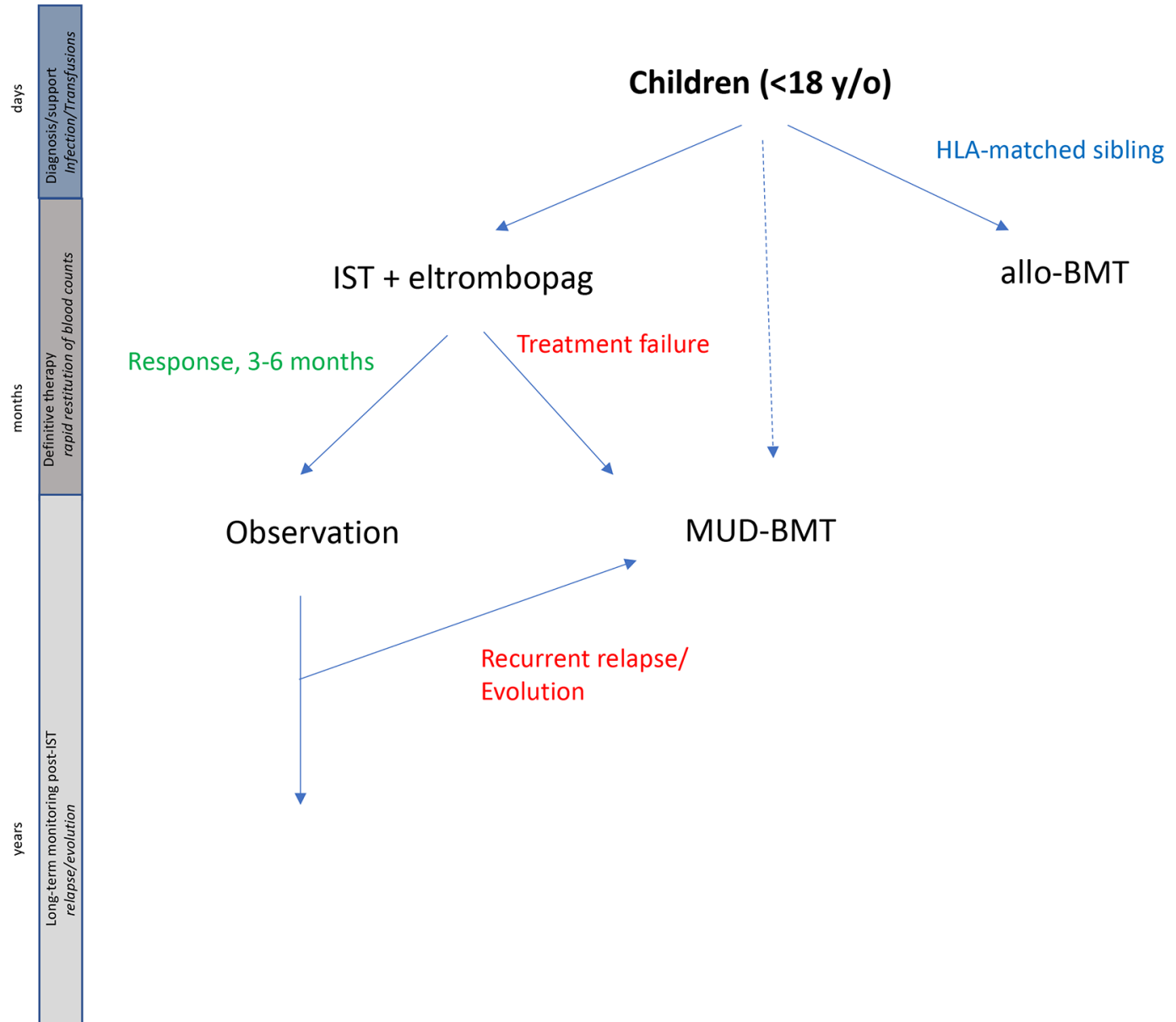

Figure 3.

Treatment algorithms for A) children and B) adults with immune aplastic anemia. Treatment strategies are not fixed, due to developing results, especially long-term, with the use of new agents like eltrombopag and transplants from alternative donors; proposed approaches are indicated with dashed arrows. The ordinate bars represent the stages of treatment: days to diagnose and stabilize the severely pancytopenic patient; months to select, implement, and complete definitive therapy; and years of monitoring for responses and complications. The ability to salvage the extremely susceptible neutropenic patient ${ }^{105}$ is fundamental to longterm outcomes. Undesirable delays from diagnosis to transplant should be avoidable when outcomes from immunosuppression are clear in 3-6 months. Patients who fail immunosuppression ${ }^{70,106103}$ or who develop complications ${ }^{107}$ can do well with second-line transplant. IST=immunosuppression, $\mathrm{BMT}=$ bone marrow transplantation, $\mathrm{MUD}=$ matched unrelated donor transplant. 


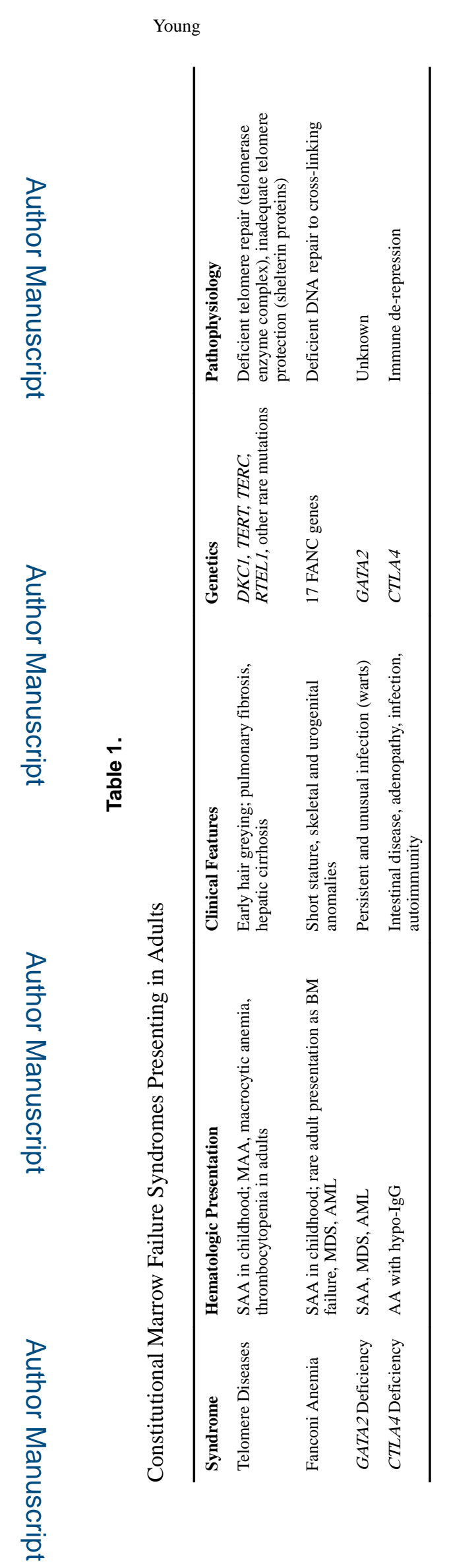

N Engl J Med. Author manuscript; available in PMC 2019 April 16. 


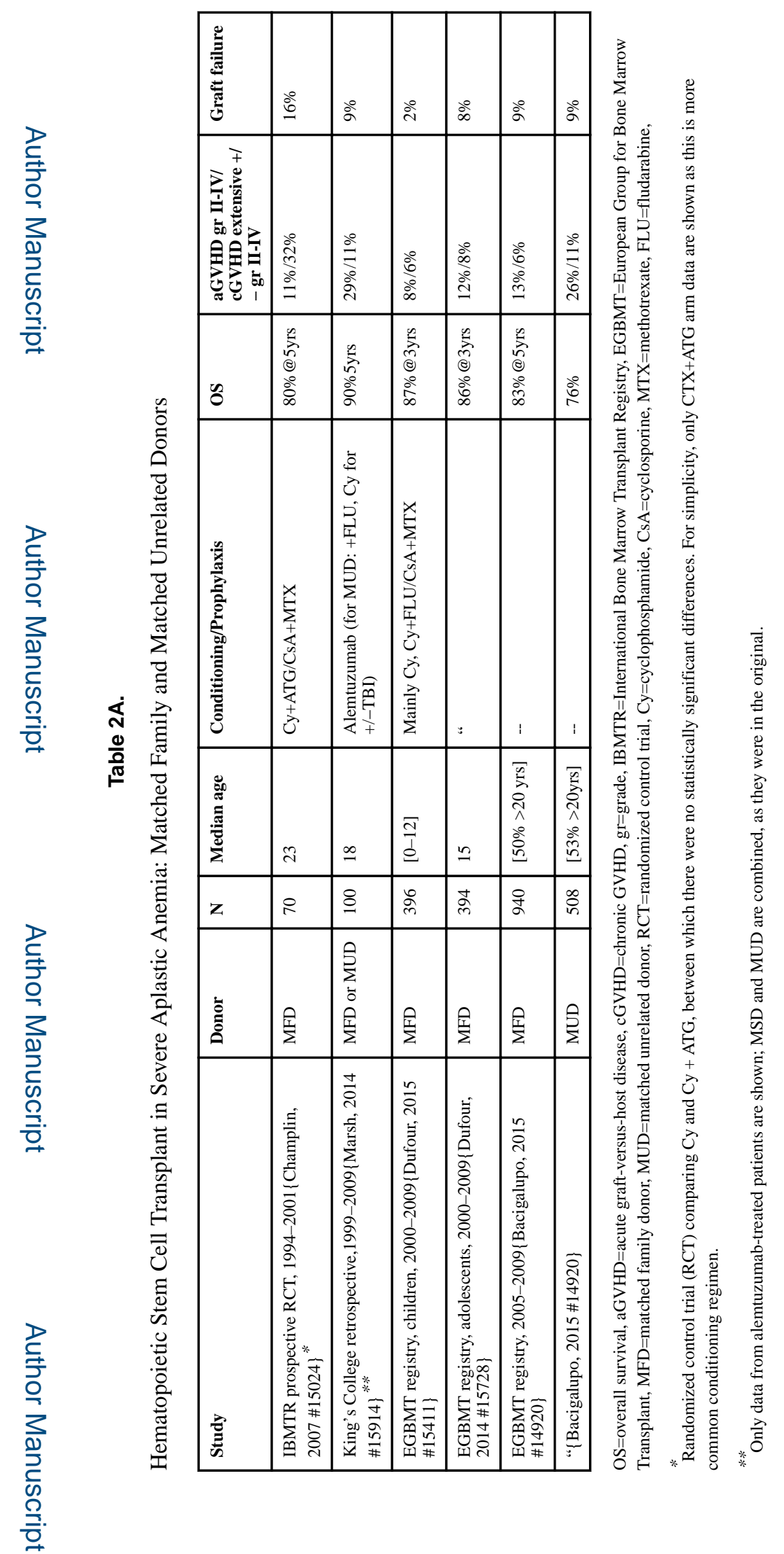

N Engl J Med. Author manuscript; available in PMC 2019 April 16. 


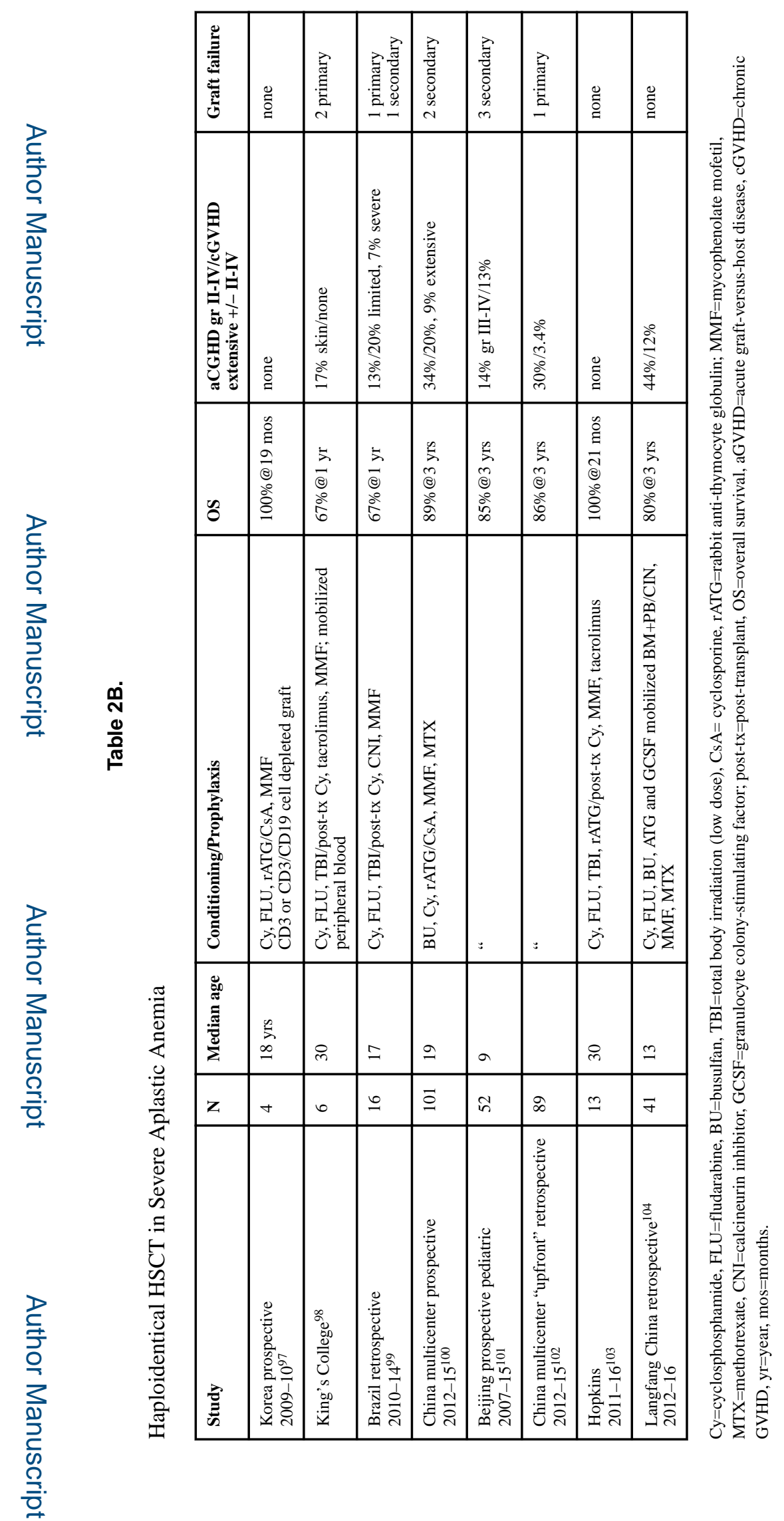

N Engl J Med. Author manuscript; available in PMC 2019 April 16. 